\title{
Practical Teaching Reform Based on Cultivation of Engineering Education and Innovation Ability for Textile Engineering Major
}

\author{
H. L. YI, Y. XUE, E. L. YANG, W. X. CHEN \\ College of Material and Textile Engineering, Jiaxing University, Jiaxing 314001, Zhejiang, P.R. China
}

\begin{abstract}
Based on the local pillar industries, to train high level application and innovation talents with ability that processes innovation spirit, practice ability and meet the needs of the local industrial development, the professional construction of colleges and local economic development are combined as the breakthrough point, and with engineering education and science and technology innovation as the main line to strengthen the engineering practice courses, the professional ability of students are progressively trained from 'verification, synthesis, design and innovation' four experiment level. On the practical teaching of integrated design, the traditional experiment curriculum are integrated, a new experimental teaching system, called as 'one main line, two platforms, three bases and four levels' is developed. The students receive the complete training, included professional education, occupation skill training, cultivation of engineering quality and innovative potential development', etc. Thus, the idea of three combinations, i.e. class inside and class outside, teaching and scientific research, school and enterprise, is developed, the engineering practice ability and innovation ability of the undergraduate students are improved remarkably.
\end{abstract}

KEYWORD: Engineering education; Talent training mode; Practical teaching system; Engineering practical ability; Innovation ability

\section{INTRODUCTION}

High education is to cultivate senior specialized talents which have creative spirit and practical ability $^{[1]}$. How to construct education system which can adopt to develop innovative education and cultivate innovative talents becomes important mission of higher education institution. However, cultivating innovative ability and practical ability is an old problem which is easy to promote but is hard to put into effect. There is no a good method to deal with the problem. Thus, 'high scores and low abilities', 'think yourself above businesses, 'Highly educated low capacity' those problems are not solved fundamentally by many colleges ${ }^{[2]}$. Therefore, taking what kind of teaching methodologies and means to improve students' innovative and hands-on ability and the overall quality of students during process of cultivating talents become one of target of cultivate talents. This is also a problem that is needed to resolve by universities of education reform in the new period ${ }^{[3]}$. For intensifying engineering ability, cultivation of engineering quality in higher engineering education and promoting human resource development and social demand being able to link up with each other, Chinese Ministry of
Education has practiced engineering education subject accreditation system, carry through 'Excellent Engineer Plan', Many specialists and experts have studied and explored in setting goals, system construction, cultivation of engineering consciousness aspects of engineering practical education ${ }^{[4]}$. However, Comparing with foreign universities' engineering education, Higher Engineering education and cultivating undergraduate students' innovative ability in China is weaker than foreign universities so far. The bottlenecks (practice teaching links) of undergraduate students are needed to break through.

\section{REASEARCH CONTENT AND METHODS}

The entry point is combining local universities and development of economy. Engineering education and scientific and technical innovation is main line. Improving undergraduate practical capacity and independent innovation ability should rely on exploring practical platform construction and new practical teaching schema, constructing practical education system which is well-organized and specific targets through scientific research training and practice. 


\subsection{Optimizing Curriculum System}

According to national and provincial relatively surveys, development of textile industry, employment of undergraduatess and feedbacks of employers, establishing cultivated targets and standards of textile and clothing wholesale talents. The aim is to promote students all-round development. The main thread is to cultivate students' practical and innovative ability. The method of teaching should be hierarchical and extend students' specialized knowledge. Eventually, realizing cultivated objectives which includes solidly based, adaptation of widely, good learning capacity, sufficient power and string hands-on skills.

Determinedly carrying through principles 'fewer and better' and 'optimal and universal' in courses' content, teaching should compress too narrow, too outdated and too miscellaneous course content. Using modern means of teaching and multimedia technology enhances efficiency and effectiveness in classroom teaching. The aim is to leave necessary time for basic scientific research training of different directions cultivation, practical teaching link and cultivating students' innovation capability. Instance of, teach can set up 'An Introduction to Textile' in the fresh year and guide students to realize professorial content and basic necessarily knowledge in fundament level. In the fresh year short semester, 'Cognition Practice' course is set. For sophomore students, textile specialized courses are set to help students understand specialized knowledge in perceptual knowledge, accumulate practical experience initially and strength students' purposiveness and interest for follow-up study. Textile specialized courses is set according to factory product processing technological process (Textile materials, spinning, weaving, dyeing etc.). 'Textile Design' course ('Fabric with the CAD Design', 'Fabric Design and Proofing', 'Sample Analysis' etc.) is set externally and increase majority of specialized courses' practical class hours for teachers to carry forward live teaching so that enhancing practicality of major courses and reducing the distance of theory teaching and practical application.

\subsection{Optimizing Experimental Teaching Content}

Optimizing experiment teaching system and experiment teaching content further, basic experiment skill training, comprehensive experimental ability training and scientific research multi-level overall coordination and combination of the experiment teaching system are constructed. Teachers' studios, internet, multimedia, computers etc. means should be used effectively for heuristic and discovery teaching. Facing local economic construction's researches help to promote education reform. Teaching implements 'Able to Grind',
'Promoting Teaching by Research', 'Combining Teaching with Research', 'Promoting Teaching and Research Together'. Letting seemed isolated experiment become a series of relative experiments in 'Textile' course is a good example. In a series of experiments, students complete yarn varieties according to the requirements in computer technology design. Firstly, spinning roving uses cotton sliver by roving frame and measures weight of each roving bar and ratio of weight unevenness. Then specified yarn varieties can be made by using the roving and strength of spun yarn, ratio of elongation at break, gram, weight and the irregularity, hairiness etc. are measured as well. Assuming that result is eligible, it indicates spinning can begin formally. If having ineligibles samples, it shows technology is needed to adjust until all samples are eligible. Students' initiation and emphasis of experiments can increase a lot by having a series of experiment.

As a result, students treat each experiment very seriously because students are afraid of this failure of this experiment having influences in next experiment's conclusion. In addition, students are able to actively focus on theoretical analysis and discussion of experiment phenomena and experimental results. Meanwhile, when problems happen during experiments, tutors should guide and inspire students gradually rather than directly give the correct answers to students. Letting students apply learned theories and knowledge to analyze problems and reasons. Eventually, students are able to solve the problems by themselves. According to the situation, students reflect that they can really gain a lot by this teaching method. Students' abilities of analysis and solving problems and manipulative ability improved a lot. Some students mention that 'A series of experiments cultivate scientific and correct attitude to treat experiments for students'; 'A series of experiments improve abilities of discovering problems and solving problems. In addition, a series of experiment help students to master knowledge in system method and understand textile specialized knowledge which is taught in classes'.

\subsection{Establishing New Practice Teaching Ideas}

Setting up 'engineering education and science and technology innovation as the main line, the coordinated development of knowledge, ability and quality' of the education ideas, from the 'verification, comprehensive, design and the innovative experiment' the four levels of progressive training students' professional ability. To integrated design of the experimental teaching, integrating the traditional experiment course, actively explore the experimental teaching mode of 'diversity', build the 'one main line, two platform, three base, four levels' 
of the experimental teaching system, realized the students 'professional foundation education to vocational skills training, engineering quality and innovation potential development' of the whole process of training.

In professional course design, professional practice and graduation project in the course of the practical teaching, such as not only emphasize to consolidate and strengthen the theoretical knowledge, but also pay more attention to students to discover problems, ask questions, problem analysis and problem solving ability and the cultivation of innovative thinking, especially in the graduation thesis, students are encouraged to practice and solve problems in application consideration. Students with actual production problems, purposefully to design reasonable experiment scheme, a key to do experiments, so as to give full play to students' subjective initiative, change passive to active experiments, and can predict the result of the experiment in scientific experiments, can take the initiative to find and solve problems, use what they have learned theoretical knowledge to analyze the experimental results and, thus makes the students' engineering consciousness is greatly increased.

\subsection{Playing a role of course contests}

University students' extracurricular science and technology innovation and all kinds of competitions are to further expand traditional experiments and practice teaching system, as well as the soil of excellent innovative talents growth. From the national, provincial, school, hospital etc., has the characteristics of subjects of science and technology innovation contest activities, enlarge the breadth and universality of extracurricular academic science and technology activities, emphasizing both school students' extracurricular science and technology activities of the organization, planning and guidance, organize regular academic report, the scientific research competition, also attaches great importance to the university of science and technology academic lectures, competition organization. Make full use of existing teaching resources, encourage students according to their own special skills and interests, independence or for teachers under the guidance of scientific research, technical development, course contests, and all kinds of social practice activities, which works creation and give financial support and condition of protection. 'Challenge cup' in Zhejiang province comprehensive extracurricular science and technology competition, such as combination of textile design, costume design, industrial design, graphic design, multimedia design and other professional course contests, vigorously develop the students' innovation consciousness and practice ability, not only repeated success, and a series of physicochemical achievements have been made.

By conducting more level, has the characteristics of science and technology innovation contest of subjects, for students to build the innovation platform of science and technology, create conditions for students to enter the laboratory, laboratory also make full use of teaching resources. So that students in different stages of learning by the cultivation of practice ability, innovation consciousness and training.

\subsection{Intensifying construction of campus practice teaching software and hardware}

From 2009 to now, materials and textile engineering experiment center, art and design experiment center have won 8 laboratory projects which are supported by national treasury, Zhejiang Finance and accumulating investing laboratory construction fee around 10 million. Relying on platforms of 'Textile Engineering' provincial key built disciplines, provincial key scientific and technological innovation team, Provincial key laboratory and key construction professionals, implementing university subjects' construction and coordinated development of subject construction and laboratory construction forms initially from 'Textile fiber(including polymer materials) $\rightarrow$ Spinning $\rightarrow$ Weaving (including nonwoven materials) $\rightarrow$ Dyeing $\rightarrow$ Costume Design $\rightarrow$ Clothing Manufacturers ' which is comprehensive, systematic, characteristic experiment teaching and sharing research platform.

\subsection{Intensifying the Fundament Construction of Off- campus Practical Teaching}

When intensifying universities' experiments teaching, enhancing students' perceptual knowledge of actual production and improving students' acceptance of studying subject and consciousness, project team also focuses on off-campus teaching practice base construction. Mainly directly thought is established by 'Mainly facing enterprises' through universities and enterprises cooperation alliance and results in explicitly cultivated objective textile engineering subject talents and have better pertinences. In universities and enterprises combining cultivating talents, it should focus on cultivating talents' abilities. In details, students should enter enterprises to have practical learning. Tutors should go to enterprises to do practices and researches. Inviting enterprises' senior technologies who are veteran to have tuition for students and bringing textile enterprises' advanced technologies, equipment and problems in producing, universities Enterprise joint product research and development center is set up to deal with these problems. 


\subsubsection{Establishing mutually beneficial of university- enterprise cooperation mechanism}

In market economy, enterprises, universities, students construct three pairs supply and demand relation which are resources for each other. In essence, it is interest relationship. Enterprises need universities provide human resource. Students need gather skill and be employed. Universities need improve education level and research level. In producing and studying, making enterprises' and universities' resource supplement in long-term requires to building universities and enterprises alliance operation mechanism which put 'reciprocity and mutual benefit', 'complementing each other' as core.

In recent years, relying on the Key Scientific and Technological Innovation Team and key laboratory of Zhejiang Province, universities provide intelligence supplement for local enterprises actively. For examples, universities help enterprises cultivate staffs and middle managers and complete enterprise management system which is center of technology. Accepting enterprises' delegation conducts to develop and study projects. Associating declaration science and technology projects and new products with enterprises conduct product development and make marketing plan. For enterprises, they should support university's teaching activities from all aspects so that it can enhance cooperation relationship between universities and enterprises and construct common development mechanism of universities education and provide technology services for enterprises.

\subsubsection{Innovating base management system of practical teaching}

Fist is constructing team, universities and enterprises cooperation organization coordination mechanism should be built. Constructing universities and enterprises cooperation lead group which are consist of university leader and enterprises' officials, the group are responsible to make practical teaching plan and implement scheme. Solving education important and difficult problems plays universities and enterprises advantages. Teaching process and quality should be supervised regularly so that supporting powerful guarantee for development of practical teaching.

Second is making protocol, management system of regular target should be presented. When making 'Textile and apparel professional education university-enterprise cooperation union constitution', universities should conclude universities and enterprises cooperation protocol so that organized framework, running mode and cooperated duration are explicit. In addition, stipulating responsibilities and obligations of universities and enterprises cooperation in all aspects is also very important.
Third is making scheme, practical teaching management methods should be operative. Combining enterprises' real requirements, implement should stipulate all subjects' practical teaching content, teaching schedule, list of tutors and time management and so on so that training's or practical work's pertinence is enhanced.

Fourth is focusing on efforts of implementation. Supervising and inspecting system should be constructed. Universities and enterprises cooperation leading group should hold work analysis conference every semester. Besides, leading group also need to develop teaching effect supervision inspection activities for restraining cooperation behaviours and enhancing practical teaching quality providing active promoting effects

\section{SUMMARY}

The research has already been applied on 2010 academic year to 2013 academic year Jiaxing University's textile engineering undergraduates. There are about 320 students getting benefits directly from the teaching revolution. Students' practical abilities have improved significantly. In recent three years, 58 undergraduates science and technology projects are won by students which are university and above level and won about 200 thousand Yuan to support these projects. There are 34 technology work contest awards which include national and provincial level winning by students. Students won 7 patents and published 18 research papers. The employers are more satisfied with performance of practical ability according to undergraduates tracking survey. The cultivated innovative applied talents which adapt to area of Jiaxing economic development are welcomed by enterprises. The employment rate of fresh undergraduates keeps 100 percent for last four years. Acceptance rate of master education increases from $10.3 \%$ to $20.1 \%$ during 2009 to 2012 and $70 \%$ of them are admitted by ' 211 ' project and above level universities. The university also won 'Advanced group of Jiaxing University undergraduates employment' for last three years. From this, the research results can enhance textile engineering subject practical teaching efficiency increasing, cultivate more, better and having better adaptive capacity and being welcomed by employers excellent talents. Overall, this teaching theory and method are worth promoting for other education organization.

\section{ACKNOWLEDGEMENT}

This work was financially supported by the Key Teaching Reform Project of Jiaxing University (No. 85151202, No. 42152003). 


\section{REFERENCES}

[1] Tan, Z., Cao, H.Y. \& Lu Y.M. 2011. Reform of practice teaching and cultivation of innovation ability. Journal of Architectural Education in Institutions of Higher Learning 20(1):116-118.

[2] Zhang, S. 2012. Causes and countermeasures of the status quo of contemporary college students'high scores but low abilities'. The Guide of Science \& Education (22):98, 117.
[3] Yang, P., Li R.F., Wang F.J., et. al. 2011. On developing students practice and creative ability in medical colleges. Chinese Journal of esthetic Medicine 20(2):294-295.

[4] Wang F., Zhang H., Chen F.Q. 2012. Investigation and practice of engineering practice teaching mode for undergraduates of chemical engineering and technology. Higher Education in Chemical Engineering (2):76-78. 